\title{
Os fatores críticos que influenciam a motivação de uma equipe de vendas no varejo da moda feminina.
}

Entender os aspectos relacionados às equipes de trabalho tem sido um dos desafios para os empresários nas últimas décadas. Mais do que isso, compreender profundamente os perfis e os fatores que influenciam as pessoas para cooperar em prol dos objetivos propostos, tornou-se foco dentro das empresas. $O$ objetivo principal deste estudo foi de identificar os fatores críticos que influenciam a motivação de uma equipe de vendas para atingir as metas no varejo da moda feminina. Além disso, traçou-se o perfil das vendedoras e analisou-se a relação entre os principais fatores críticos motivacionais e os resultados compilados destes perfis. Para coletar as informações utilizou-se de um questionário estruturado com quinze questões de múltiplas escolhas enviado por e-mail para cinquenta vendedoras de uma empresa do varejo da moda feminina, caracterizando-se como uma pesquisa quantitativa. Utilizou-se também de pesquisa documental e observação do participante. Considerou-se para a análise e discussão dos dados os dois fatores críticos positivos e negativos que influenciam uma equipe de vendas para atingir as suas metas. Apontou-se como fatores críticos positivos "ter desafios constantes e ser reconhecido como um bom profissional pelos líderes e subordinados". Como fatores críticos negativos, elegeu-se pelos respondentes "possibilidade de crescimento na empresa e participar nas decisões estratégicas da empresa". Diante dos resultados da pesquisa, sugeriu-se ações para melhorar a motivação e o desempenho das vendedoras.

Palavras-chave: Relações Humanas; Motivação; Equipe de Vendas.

\section{The critical factors that influence the motivation of a sales team at female fashion retail}

Understanding the aspects related to the work teams has been one of the challenges for the businessmen over the last decades. Besides that, comprehending deeply the profiles and factors which influence people to cooperate on behalf of the proposed objectives has become the focus inside the companies. Therefore, the main aim of this study was to identify the critical factors which influence a sales team to reach the goals in the female fashion retail. Yet, the profile of the saleswomen was identified and the relation among the main motivational critical factors and the results of these profiles were analysed. To collect the information, a structured questionnaire with multiple choice questions was used, sent by e-mail to fifty saleswomen of a female fashion retail company, characterized as a quantitative research. Yet, a documental research and participant observation were used. For the analysis and data discussion, the two positive and negative factors which influence a sales team to reach its goals were considered. As positive critical factors, "having constant challenges and being honored as a good professional by the leaders and subordinates" were pointed. These factors are related to the need of self-realization, presented by Maslow (1954), at the Pyramid of Needs. As negative critical factors, "possibility to grow in the company and participate in the strategic decisions of the company" were elected by the respondents. A relation with the profile of the sales team was identified. The sales team age is between 18-25 years old, single marital status, with high school education and the saleswomen live alone. Maslow (1954) points that not all people have the ambition to grow or be noteworthy in the working environment because the focus is on their basic and physiological needs and security. On behalf of the research results, a climate research was suggested among the saleswomen, in order to be possible to observe the opinions about the aspects regarded to the working environment, motivation, relationship among coworkers, subordinates and leader. Other recommendations were made to the company, such as creating internal competitions among the saleswomen and highlighting those who obtain the best results. With that, it is expected to create a healthy competition, avoiding them to get the "comfort zone".

Keywords: Human Relationship; Motivation; Sales Team

\section{Topic: Recursos Humanos}

Reviewed anonymously in the process of blind peer

\section{Andre Kohl}

Universidade de Santa Cruz do Sul, Brasil http://lattes.cnpq.br/4410944819672175 andre kohl2001@yahoo.com.br

\section{Ismael Bianchetti}

Universidade de Santa Cruz do Sul, Brasil ismaelbianchetti@gmail.com
Received: 15/01/2017

Approved: 16/03/2017
Referencing this:

SEIBT, N. G.; SOUZA, A. A.. Os fatores críticos que influenciam a motivação de uma equipe de vendas no varejo da moda feminina. Revista Brasileira de Administração Científica, v.8, n.1, p.131-140, 2017. DOI: http://doi.org/10.6008/SPC2179-684X.2017.001.0011 


\section{INTRODUÇÃO}

O mundo empresarial no qual vivemos hoje, aliado ao alto nível de exigência interna e externamente nas organizações, faz com que trabalhamos pressionados por um alto nível de produtividade necessária para manter a empresa ativa. No varejo, atender e satisfazer o cliente com excelência é o grande passo a ser conquistado. Portanto, é preciso uma gestão de pessoas eficiente para tornar este processo rentável e satisfatório entre todas as partes envolvidas. Segundo Marras (2009), fazer gestão também significa entender o comportamento dos colaboradores e o que os motiva a serem cada vez mais produtivos dentro do ambiente de trabalho.

Diante do exposto, se faz necessário compreender o que motiva uma equipe de vendas e como a empresa pode atuar frente aos resultados apresentados, de modo a obter maior eficiência em sua operação de negócio. Portanto, o problema de pesquisa é: o que influencia uma equipe de vendas para atingir suas metas no varejo da moda feminina? Este estudo se realizará com base na operação de varejo da empresa Alfa, cuja organização está situada na cidade de Porto Alegre, RS. A Alfa possui 200 colaboradores e atua no ramo do vestuário feminino com desenvolvimento próprio dos seus produtos, comercializando-os nos canais de vendas das suas 15 lojas Próprias, 27 lojas franquias e pelo atacado no modelo de lojas multimarcas.

O objetivo geral é identificar os fatores críticos que influenciam uma equipe de vendas para atingir as metas no varejo da moda feminina. Como objetivos secundários: traçar o perfil das vendedoras de uma empresa do varejo da moda feminina; apresentar fatores críticos que influenciam as vendedoras para atingir as metas numa empresa do varejo da moda feminina; analisar a relação entre os principais fatores críticos motivacionais e os resultados compilados do perfil das vendedoras de uma empresa do varejo da moda feminina; ponderar sugestões para melhorar o desempenho das equipes de vendas a partir dos principais fatores críticos motivacionais identificados neste estudo.

As empresas que atuam na área de vendas buscam constantemente melhorar o desempenho da operação através de uma série de aspectos como tecnologia, sistema de informação, layout de loja, melhoria nos produtos, entre outras questões. Mas, a dependência por pessoas altamente qualificadas e motivadas para alcançar os objetivos propostos, continua intensa. $\mathrm{O}$ ambiente de trabalho é constituído por diferentes perfis e comportamentos, o que exige importantes habilidades para entender e compreender os fatores críticos que levam as pessoas à produzirem mais e melhor. Portanto, este estudo justifica-se pela necessidade de conhecer e entender os fatores críticos que influenciam uma equipe de vendas a alcançar as suas metas no varejo da moda feminina.

\section{REVISÃO TEÓRICA}

\section{A origem das relações humanas}

Este capítulo apresenta a fundamentação teórica sobre a origem da teoria das relações humanas; a experiência de Hawthorne e suas conclusões; teoria comportamental; motivação no trabalho; avaliação de desempenho; clima organizacional. Segundo Chiavenato (2003), a teoria das relações humanas surgiu nos Estados Unidos como consequência das conclusões da Experiência de Hawthorne, desenvolvida por Elton 
Mayo e colaboradores. Foi um movimento de reação e oposição à Teoria Clássica da Administração. Chiavenato (2003) apresenta os principais fatos que deram origem a esta teoria:

A necessidade de humanizar e democratizar a administração, libertando-a dos conceitos rígidos e mecanicistas da Teoria Clássica e adequando-os aos novos padrões de vida do povo Americano;

O desenvolvimento das ciências humanas, principalmente a psicologia, bem como sua crescente influência intelectual e suas primeiras aplicações à organização industrial. As ciências humanas vieram demonstrar a inadequação dos princípios da Teoria Clássica;

As ideias da filosofia pragmática de John Dewey e da Psicologia Dinâmica de Kurt Lewin, foram fundamentais para o humanismo da Administração. Elton Mayo é o fundador da escola;

As conclusões da Experiência de Hawthorne, realizada entre 1927 e 1932, sob a coordenação de Elton Mayo, que puseram em xeque os principais postulados da Teoria Clássica da Administração.

\section{A Experiência de Hawthorne}

Em 1924, foi realizada uma pesquisa junto à Academia Nacional de Ciências dos Estados Unidos visando verificar a correlação entre produtividade e iluminação do local de trabalho. Pouco antes, Mayo havia conduzido uma pesquisa junto a uma empresa têxtil, cuja rotatividade chegou a $250 \%$ ao ano, perante vários esquemas inúteis de incentivos salariais. Então, Mayo introduziu um intervalo de descanso, proporcionou que os operários decidissem sobre horário de produção e contratou uma enfermeira. Isto gerou um espírito de grupo, aumentando a produção e reduzindo a rotatividade do pessoal.

Em 1927, junto a empresa Western Electric Company, situada em Chicago, o Conselho Nacional de Pesquisas iniciou uma experiência na fábrica para avaliar a correlação entre iluminação e eficiência dos operários, medida por meio da produção. Elton Mayo coordenou esta experiência, estendendo-se à fadiga, acidentes no trabalho, rotatividade do pessoal e ao efeito das condições de trabalho do pessoal. Os pesquisadores chegaram à conclusão de que os resultados eram prejudicados por variáveis de natureza psicológica, então tentaram neutralizar ou até mesmo, eliminar o fator psicológico, o que fez a experiência se entender até o ano de 1932.

\section{Conclusões da Experiência de Hawthorne}

A Experiência de Hawthorne proporcionou o delineamento dos princípios básicos da Escola das Relações Humanas. Dividindo-a e explicando de forma construtiva, buscando conceituar de forma clara e objetiva acerca da temática proposta, teve-se oito observações. Suas conclusões, relacionada à sua experiência, foram:

O nível de produção é resultante da integração social: diferentemente do que dizia a Teoria Clássica que a produção era determinada pela capacidade física ou fisiológica, Hawthorne concluiu que, quanto maior a integração social do trabalhador no grupo, tanto maior será sua eficiência;

Comportamento social dos empregados: o comportamento social dos colaboradores é apoiado no grupo, não agindo ou reagindo como indivíduos, mas como membros de grupos. Isso significa que a empresa não pode tratar, um a um, como se fossem isolados. Precisa trata-los como membros de grupos sujeitos a influências sociais desses grupos; 
Recompensas e sanções sociais: as normas e os padrões sociais condicionam o comportamento dos trabalhadores. Conforme a experiência feita com os operários, aqueles que produziram acima ou abaixo da norma socialmente determinada, perderam o respeito e a consideração dos colegas. Portanto, cada grupo desenvolve suas crenças e expectativas em relação à empresa, sejam reais ou imaginárias, e isto influencia as atitudes e o comportamento de cada indivíduo;

Grupos informais: a Teoria Clássica se preocupava com os aspectos formais da organização como autoridade, responsabilidade, estudos de tempos e movimentos, etc. Já os autores da Teoria Humanista, concentravam nos aspectos informais como, grupos informais, atitudes, expectativas, etc. Os grupos informais definem suas regras de comportamento, recompensas, sanções sociais, objetivos, valores sociais, crenças, entre outros, e a empresa passou a ser visualizada como uma organização social composta por grupos sociais informais;

Relações humanas: cada indivíduo participa de grupos sociais no local de trabalho e mantêm-se em uma constante interação social. A Teoria das Relações Humanas passou a estudar essa interação, entendendo que cada pessoa possui uma personalidade própria e diferenciada que influencia no comportamento e nas atitudes das outras pessoas do grupo. Portanto, o comportamento humano é influenciado pelas atitudes e normas informais existentes nos grupos de trabalho e isto precisa ser entendido pelos administradores, criando uma atmosfera que encoraja as pessoas a exprimir-se de forma livre e sadia;

Importância do conteúdo do cargo: Mayo e seus colaboradores verificaram que a especialização proposta pela Teoria Clássica não cria a organização mais eficiente. Observaram que os operários trocavam de posição para variar e evitar a monotonia, mesmo que contrariando a política da empresa. Isso gerava efeitos negativos na produção, mas elevava o moral do grupo. Os trabalhos repetitivos e maçantes influenciam a atitude do colaborador, o que afeta a produtividade dele;

Ênfase nos aspectos emocionais: os elementos emocionais não planejados e irracionais do comportamento humano merecem atenção especial das empresas.

\section{Teoria Comportamental e Motivação no Trabalho}

Segundo Chiavenato (2003), a Teoria Comportamental surgiu no final da década de 1940 e originouse da oposição que a Teoria das Relações Humanas fez sobre a Teoria Clássica. Essa nova teoria passou a representar uma síntese da teoria da organização formal com o enfoque das relações humanas e seus desdobramentos. Muitos estudiosos defendem a tese de automotivação, ou seja, que cada pessoa deve ser motivada por si própria, pelas suas questões pessoais e necessidades. Outros acreditam que a motivação é gerada por fatores externos. Segundo Maslow (1954), a motivação dos indivíduos objeta satisfazer certas necessidades que vão desde as primárias (fisiológicas) - das mais simples até as mais complexas (autorrealização).

A Teoria Comportamental fundamenta-se no comportamento individual das pessoas, aprofundando um estudo sobre a motivação humana para poder explicar como as pessoas se comportam. Esta teoria verificou que o Administrador precisa conhecer as necessidades humanas para melhor compreender o comportamento humano e por meio da motivação humana, melhorar a qualidade de vida dentro das organizações e com isso, aumentar a produtividade das pessoas (CHIAVENATO, 2003). Há muitas discussões sobre motivação. 


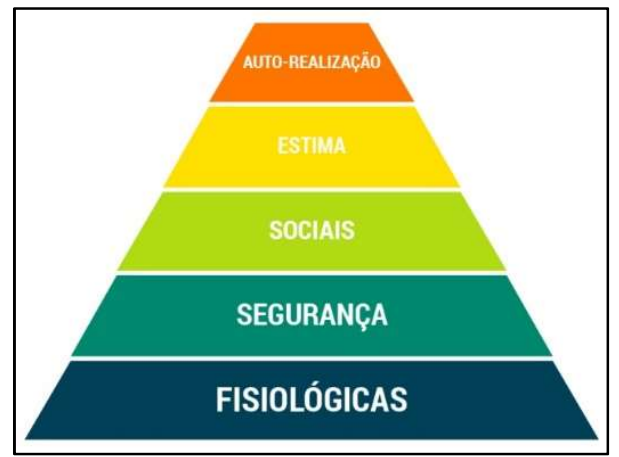

Figura 1: Pirâmide de Maslow.

Marras (2009), cita os tipos de necessidades e o que cada uma representa baseada na teoria de Maslow, sendo elas: fisiológica: são necessidades físicas como sexo, bebida e comida; segurança: estabilidade, proteção, livre do perigo e uma estrutura; social: ter amizades, vínculos, familiares e convívio; estima: se sentirem valorizadas, autoestima e sentir-se competente; e autorrealização: o desejo de renovar e reciclar o seu potencial.

Para Marconi et al. (2013), os fatores motivacionais estão sob o controle do indivíduo, pois estão relacionados com aquilo que ele faz e desempenha. Envolvem sentimentos, reconhecimento profissional e autorrealização, e dependem das tarefas que o indivíduo realiza no seu trabalho. Quando as necessidades mais baixas estão sendo atendidas, as necessidades nos níveis mais elevados passam a dominar o comportamento. Contudo, quando alguma necessidade de nível mais baixo deixa de ser satisfeita, ela volta a predominar o comportamento (MARCONI et al., 2013).

\section{Avaliação de desempenho}

Desempenho humano é o ato ou efeito de cumprir ou executar determinada missão ou meta previamente traçada. É diretamente proporcional a duas condições do ser humano: o "querer fazer e o saber fazer" (MARRAS, 2009). A avaliação de desempenho procura fornecer aos empregados informações sobre sua própria atuação, de forma que possa aperfeiçoá-la sem diminuir sua dependência e motivação para fazer um bom trabalho (MILKOVICH et al., 2010). Segundo Tachizawa et al. (2006), a avaliação de desempenho pode ser considerada um dos mais importantes instrumentos de que dispõe a administração de uma empresa para analisar os resultados da sua atuação de sua força de trabalho e para prever posicionamentos futuros, considerando o potencial humano disponível em seus quadros.

\section{Clima organizacional}

O clima organizacional é importante para que os objetivos de uma organização sejam alcançados. Depende dele para manter colaboradores ativos, focados e motivados a executar suas funções. Segundo Oliveira (2004), devido à adversidade interpessoal e interdepartamental, existem vários climas internos manifestando-se concomitantemente na organização. A realização de pesquisas junto aos funcionários, no intuito de avaliar seu perfil e seu grau de motivação, satisfação integração, pode trazer subsídios para a análise das diferentes culturas normalmente presente na maioria das organizações. Para Tachizawa et al. 
(2006), o clima organizacional é o grau de satisfação demonstrado pelos membros de uma organização na qual a motivação é o fator fundamental para a realização dos trabalhos.

\section{METODOLOGIA}

Os procedimentos metodológicos, segundo Gil (2007), são o momento em que o investigador estabelece os meios técnicos da investigação prevendo-se os instrumentos e procedimentos necessários utilizados para a coleta de dados. Este item responde: Como? Com quê? Onde?. Os procedimentos metodológicos apresentam os seguintes elementos: Caracterização da pesquisa: Segundo Gil (2008), a caracterização da pesquisa consiste em informar o desenho que a pesquisa terá, ou seja, se a pesquisa será quantitativa ou qualitativa.

Para Denzin et al. (2006), a pesquisa qualitativa baseia-se em perspectivas construtivas e participativas, sendo de caráter exploratório, permitindo que os entrevistados pensem livremente sobre o tema. Envolve o estudo do uso e a coleta de uma variedade de materiais empíricos e, como um conjunto de atividades interpretativas, não privilegia nenhuma única prática metodológica em relação à outra. Diante dessas características, as autoras definem genericamente e de maneira inicial que "a pesquisa qualitativa é uma atividade situada que localiza o observador no mundo" (DENZIN et al., 2006).

A pesquisa qualitativa é utilizada quando se busca percepções e entendimento sobre a natureza geral de uma questão, abrindo espaço para a interpretação. Já a pesquisa quantitativa, segundo Sampieri et al. (2006), oferece-nos a possibilidade de generalizar os resultados de uma maneira mais ampla, concedendo um ponto de vista de contagem e magnitude em relação aos fenômenos. Acrescenta Sampieri et al. (2006) que o enfoque quantitativo utiliza a coleta de dados para testar hipóteses com base na medição numérica e na análise estatística para estabelecer padrões de comportamento.

Diante das características apresentadas, podemos concluir que este estudo terá um viés quantitativo, pois o aluno realizará pesquisa junto às vendedoras de uma empresa do varejo da moda feminina, e as informações serão coletadas através de um questionário com questões de múltiplas escolhas, que será encaminhado e devolvido via e-mail sem a presença do pesquisador, de modo a atender os objetivos do estudo.

Tratando-se de Delimitação da pesquisa, dentro do tema que aborda o trabalho é necessário limitar qual o método de pesquisa que será utilizado para atingir o objetivo proposto. É nesta parte que apresentamos os métodos que utilizaremos pra a coleta e análise dos dados. Além de delinear o que é a pesquisa e onde aplicaremos a ferramenta utilizada para a coleta de dados. Segundo Gil (2008), toda e qualquer classificação se faz mediante critérios. A pesquisa possui sua classificação baseada nos seus objetivos.

Para manter o viés da pesquisa voltado aos objetivos do estudo não serão explorados os processos internos da organização, permitindo que o foco esteja direcionado nos aspectos relacionados ao público-alvo em questão. Por fim, não participarão da pesquisa as vendedoras do canal de lojas Franqueadas e Atacado. 
Este estudo se caracteriza como uma pesquisa quantitativa, pois o aluno utilizará um questionário estruturado com questões de múltiplas escolhas, aplicado junto às vendedoras da Rabusch que atuam nas lojas próprias, visando entender quais os fatores críticos que às influenciam para atingir suas metas. A população deste estudo é representada por um total de 100 vendedoras e destas, 50 participaram da pesquisa, obtendo-se assim uma amostra de 50\%. Segundo Marconi et al. (2013), o desvio padrão é a medida de variabilidade de mais larga aplicação nos trabalhos estatísticos.

Quando se refere a Técnicas e instrumentos de coleta de dados, utilizou-se dos seguintes instrumentos: questionário, pesquisa documental e observação do participante. O questionário deste trabalho constituiu-se de quinze questões fechadas e de múltiplas escolhas. Para Fachin (2006), questões fechadas são aquelas em que o pesquisado escolhe sua resposta em um conjunto de categorias elaboradas juntamente com a questão. Essas questões direcionam o pesquisado para alternativas já estruturadas; não havendo liberdade para que ele expresse sua opinião. Tais questões são geralmente preferidas pela população pesquisada, por serem de fácil entendimento e mais práticas de serem respondidas.

Conforme Mattar (2006), depois de construído o questionário, deve ser revisado para se chegar ao melhor formato possível. Feito isto, o pré-teste é realizado com o objetivo de verificar se os termos utilizados são compreendidos pelos respondentes, se as questões estão sendo bem interpretadas e se não existem objeções em relação às respostas. O pré-teste é muito importante no que se refere ao aprimoramento do questionário utilizado na pesquisa.

O pré-teste deste questionário foi aplicado a 5 (cinco) colaboradoras das áreas internas da organização para que analisassem se o conteúdo e a estrutura estavam claros de tal forma que a aplicação pudesse ser eficiente e bem compreendida. A sua aplicação oficial foi realizada pelo sistema Google Docs onde cada participante do estudo recebeu via e-mail um link e ao clicar, teve acesso direto ao questionário. Após finalizar o preenchimento, o sistema enviou as respostas automaticamente ao pesquisador.

Utilizou-se também da pesquisa documental. Conforme Vergara (2004), a pesquisa documental foi utilizada e realizada através de documentos, fotos, filmes e relatórios, que geralmente estão no interior de órgãos públicos e privados e ou até em posse de pessoas físicas. O pesquisador utilizou-se de documentos da empresa para pesquisar o cadastro dos funcionários e identificar o perfil das vendedoras. Os dados também foram coletados por meio da observação e interação do pesquisador com 10 vendedoras participantes do estudo. Isso aconteceu por meio de visitas no ponto de venda da Rabusch e proporcionou mesmo que de maneira informal, uma percepção sobre os aspectos estudados e como eles acontecem na prática.

Propondo-se Técnicas de análise de dados, informa-se que os dados coletados na pesquisa foram tabulados em planilhas de Excel e estruturados através da escala Likert - 0 a 10 (zero a dez), onde 0 representa o fator crítico negativo e 10, o fator crítico positivo. Desta forma, permitiu-se criar um Score, gerando Ranking dos fatores críticos identificados na pesquisa. Segundo Marconi et al. (2013), na escala Likert as respostas para cada item variam segundo o grau de intensidade. Essa escala com categorias ordenadas, igualmente 
espaçadas e com mesmo número de categorias em todos os itens, é largamente utilizada em pesquisas organizacionais.

\section{RESULTADOS E DISCUSSÃO}

A equipe de vendas tem idade entre 18 e 25 anos, estado civil solteira, com a escolaridade de $2 \stackrel{0}{\text { grau }}$ e residem sozinhas. Estas características têm influência direta na pesquisa, pois segundo Chiavenato (2003), cada perfil possui uma necessidade. Se as personalidades e os comportamentos são diversos, é preciso entender para tirar o melhor proveito disso e atingir bons resultados nos negócios. Visando atender aos objetivos propostos neste estudo, será apresentado o perfil das vendedoras participantes da pesquisa.

Quadro 1: Perfil das vendedoras.

\begin{tabular}{|c|c|c|c|}
\hline \multicolumn{4}{|c|}{ Perfil das Vendedoras } \\
\hline Idade & $18-25$ & $26-30$ & $31-35$ \\
\hline$\%$ & $80 \%$ & $15 \%$ & $5 \%$ \\
\hline Estado Civil & Solteira & União Estável & Casada \\
\hline$\%$ & $65 \%$ & $30 \%$ & $5 \%$ \\
\hline Escolaridade & 10 Grau & 20 Grau & Superior \\
\hline$\%$ & $5 \%$ & $85 \%$ & $10 \%$ \\
\hline Reside & Sozinha & Com os Pais & Com Cônjuge \\
\hline$\%$ & $45 \%$ & $20 \%$ & $35 \%$ \\
\hline
\end{tabular}

No quadro 2 demonstra-se o resultado da pesquisa através de um Ranking. As notas apontadas pelos participantes para cada questão foram acumuladas, e após, dividido pelo número de respostas, o que gerou a média para cada questão. Esta média foi organizada na ordem decrescente, do fator que mais influencia (média maior) para o que menos influencia (média menor) uma equipe de vendas a alcançar suas metas no trabalho.

Quadro 2: Fatores críticos que influenciam as vendedoras.

\begin{tabular}{|c|c|c|}
\hline Questão & Quais os fatores que influenciam você a alcançar as suas metas no trabalho? & Nota \\
\hline 10 & Ter desafios constantes. & 9,58 \\
\hline 20 & Ser reconhecido como um bom profissional pelo líder/subordinados. & 9,52 \\
\hline 3음 & Conquistar meu espaço profissional. & 9,36 \\
\hline 4 은 & Possibilidade de servir às clientes/pessoas. & 9,28 \\
\hline 5우 & Trabalhar com pessoas que admiro e respeito. & 9,20 \\
\hline 60 & Ter um bom relacionamento com as pessoas com quem trabalho. & 9,20 \\
\hline 7은 & Fazer o que gosto. & 9,20 \\
\hline 80 & Possibilidade de colaborar com as pessoas no ambiente de trabalho. & 8,96 \\
\hline 9o & Oportunidade de me desenvolver profissionalmente. & 8,88 \\
\hline 10 은 & Adquirir bens. & 8,88 \\
\hline 11 음 & Ter liberdade/autonomia de ação. & 8,76 \\
\hline 12 은 & Ter flexibilidade de horário. & 8,40 \\
\hline 13 은 & Receber bons salários. & 8,36 \\
\hline 149 & Possibilidade de crescimento na empresa. & 8,04 \\
\hline 15 은 & Participar nas decisões estratégicas da empresa. & 7,44 \\
\hline
\end{tabular}

Os respondentes apontaram que ter desafios constantes e ser reconhecido como um bom profissional pelos líderes e subordinados, é o que influencia para alcançar as suas metas no trabalho. O primeiro fator crítico está relacionado aos aspectos de estima, que segundo Maslow (1954), as pessoas têm a necessidade de se sentirem valorizadas, competentes e com autoestima. Já o segundo, possui correlação com os aspectos de autorrealização. Conforme Maslow (1954), a autorrealização é a necessidade do ser humano de renovar 
e reciclar o seu potencial. Por se tratar de fatores críticos, considerou-se para analisar os dois principais fatores positivos e negativos, conforme grau de relevância identificado na pesquisa.

Quadro 3: Fatores críticos positivos.

\begin{tabular}{|c|l|r|}
\hline Questão & \multicolumn{1}{|c|}{ Quais os fatores que influenciam você a alcançar as suas metas no trabalho? } & Nota \\
\hline 1o & Ter desafios constantes. & 9,58 \\
\hline 2 o & Ser reconhecido como um bom profissional pelo líder/subordinados. & 9,52 \\
\hline
\end{tabular}

Percebe-se uma correlação entre os fatores críticos positivos e o perfil da equipe, representado por colaboradoras que no seu primeiro estágio profissional e perspectivas de autorrealização. Isso gera uma necessidade de buscar através dos desafios, um bom desempenho para desencadear reconhecimento perante os seus líderes e/ou subordinados com quem trabalha. No quadro 4 apresentam-se os fatores críticos negativos com base nas menores notas avaliadas pela equipe de vendas.

Quadro 4: Fatores críticos negativos.

\begin{tabular}{|c|l|r|}
\hline Questão & \multicolumn{1}{|c|}{ Quais os fatores que influenciam você a alcançar as suas metas no trabalho? } & Nota \\
\hline 140 & Possibilidade de crescimento na empresa. & 8,04 \\
\hline 15 o & Participar nas decisões estratégicas da empresa. & 7,44 \\
\hline
\end{tabular}

Um dos fatores críticos menos relevantes para a equipe de vendas no quesito motivação para o atingimento das metas, foi possibilidade de crescimento na empresa. Segundo Chiavenato (2003), nem todas as pessoas conseguem ou almejam chegar ao topo da pirâmide de necessidades. Algumas chegam a se preocupar com as questões de autorrealização, mas estacionam nas necessidades de estima e até mesmo, nas mais básicas como segurança e fisiológicas, sem que consigam satisfazê-las adequadamente.

E o fator crítico que menos influencia as vendedoras para atingir suas metas no trabalho é participar nas decisões estratégicas da empresa. Estabelece-se uma relação com a pirâmide das necessidades conforme a Teoria de Maslow (1954) e apresentada por Marras (2009), indicando que as pessoas não tem a ambição inicialmente de participar e serem influenciadoras nas decisões estratégicas de uma organização. Aspectos como um ambiente agradável, seguro e que proporcione uma interação social, são percebidos e valorizados pelas pessoas.

\section{CONSIDERAÇÕES FINAIS}

Conforme Chiavenato (2003), a Teoria Comportamental mostrou que o Administrador precisa conhecer as necessidades humanas para melhor compreender o comportamento das pessoas e por meio da motivação humana, melhorar a qualidade de vida dentro das organizações e com isso, aumentar a produtividade. Diante disso, sugere-se à empresa uma análise detalhada do comportamento das vendedoras através de uma entrevista informal, conversando com as colaboradoras e tomando nota dos aspectos relevantes por elas citados. Possivelmente, aspectos não percebidos pela organização e que implicam no desempenho, passarão a ser pauta de discussão.

Para Marras (2009), o desempenho humano é diretamente proporcional a duas condições do ser humano: o "querer fazer e o saber fazer". Por isso, tamanha a importância de ter este contato mais próximo com as vendedoras para entender melhor o seu comportamento. 
Outra sugestão é que realize-se uma pesquisa de clima com as vendedoras, permitindo observar as opiniões sobre os aspectos relacionados ao ambiente de trabalho, motivação, relação com colegas, subordinados e chefia. Conforme Oliveira (2004), a realização de pesquisas junto aos funcionários pode trazer subsídios para a análise das diferentes culturas normalmente presentes na maioria das organizações e obter melhor desempenho dos colaboradores.

Para explorar o fator crítico positivo de maior influência apresentado na pesquisa (ter desafios constantes), sugere-se desenvolver competições entre as vendedoras de modo que sintam-se desafiadas por metas, gerando uma competitividade sadia, não permitindo que entrem na chamada 'zona de conforto'. Frente ao outro fator crítico positivo (ser reconhecido como um bom profissional pelos líderes $e$ subordinados), sugere-se a empresa criar um 'destaque do mês', reconhecendo as melhores vendedoras através de uma mensagem do Presidente para as lojas, a entrega de um certificado aos colaboradores da empresa e uma foto da colaboradora em um porta-retrato autografado pelos seus chefes e colegas.

O objetivo é fazer com que as vendedoras produzam mais para serem destacadas e reconhecidas pela empresa em que atuam, alcançando os aspectos de autorrealização. Concluindo, acredita-se que os objetivos desta pesquisa foram atendidos e que as sugestões propostas possam auxiliar a empresa a melhorar o desempenho das equipes de vendas. Sugere-se a continuidade da pesquisa, pois este assunto pode ser explorado em outro viés.

\section{REFERÊNCIAS}

CHIAVENATO, I.. Desempenho humano nas empresas: como desenhar cargos e avaliar o desempenho para alcançar resultados. Barueri: Manole, 2009.

CHIAVENATO, I.. Introdução à teoria geral da administração: uma visão abrangente da moderna administração das organizações. Rio de Janeiro: Elsevier, 2003.

DENZIN, N. K.; LINCOLN, Y. S.. O planejamento da pesquisa qualitativa: teorias e abordagens. Porto Alegre: Artmed, 2006.

FACHIN, O.. Fundamentos de metodologia. 4 ed. São Paulo: Saraiva, 2006.

GIL, A. C.. Métodos e técnicas de pesquisa social. 5 ed. São Paulo: Atlas, 2007.

GIL, A. C.. Como elaborar projetos de pesquisa. 4 ed. São Paulo: Atlas, 2008.

MARCONI, M. A.. Técnicas de pesquisa: planejamento e execução de pesquisas, amostragens e técnicas de pesquisa, elaboração, análise e interpretação de dados. São Paulo: Atlas. 2013.
MATTAR, F. M.. Pesquisa de marketing. São Paulo: Atlas, 2006.

MARRAS, J. P.. Administração de recursos humanos: do operacional ao estratégico. São Paulo: Saraiva, 2009.

MASLOW, A. H.. Motivação e personalidade. New York: Harper e Row Publisher, 1954.

MILKOVICH, G. T.; BOUDREAU, J. W.. Administração de recursos humanos. 1 ed. São Paulo: Atlas, 2010.

OLIVEIRA, M. A.. Pesquisas de clima interno. São Paulo: Nobel, 2004.

ROESCH, S. M. A.. Projetos de estágio do curso de administração: guia para estágio, trabalhos de conclusão, dissertações e estudos de caso. 3 ed. São Paulo: Altas, 2006.

SAMPIERI, R. H.; COLLADO, C. F.; LUCIO, P. B.. Metodologia de pesquisa. 3 ed. São Paulo: McGraw-Hill, 2006.

TACHIZAWA, T.; FERREIRA, V. C.; FORTUNA, A. A.. Gestão com pessoas: uma abordagem aplicada às estratégias de negócios. Rio de Janeiro: FGV, 2006

VERGARA, S. C.. Métodos de pesquisa em administração. São Paulo: Atlas, 2004. 